\title{
El economista y el sociólogo: el pensamiento relacional como paradigma*
}

\author{
Sergio Lorenzo Sandoval Aragón**
}

\section{RESUMEN}

Este artículo contribuye a la reflexión acerca de las razones del distanciamiento entre las ciencias sociales, particularmente la sociología y la economía, en su proceso histórico de institucionalización y autonomía, que acabaría por oponerlas y por limitar su potencial explicativo. Se sostiene que la opción entre diferentes perspectivas epistemológicas ha estado estrechamente relacionada a unas determinadas posturas políticas y que ello puede explicar las divergencias teóricas entre esas ciencias; para ilustrar esto, se analiza un caso práctico del entorno francés. Asimismo, se argumentan las ventajas explicativas del paradigma relacional y cómo la inserción de la economía y la sociología en dicho paradigma permitiría reunificarlas y superar su pernicioso distanciamiento. También se exponen dos teorías, una sociológica y otra económica, que ejemplifican tal unificación.

Palabras clave: historia del pensamiento económico, sociología económica, heterodoxia, pensamiento relacional, reflexividad, crítica.

Clasificación JEL: B50, B52, B59, Z13.

\begin{abstract}
This article contributes to a reflection about the reasons for the gap between the social sciences, particularly sociology and economics, in their historical process of institutionalization and autonomy. This gap has opposed both disciplines and has limited their explanatory power. It is argued that the choice between different epistemological perspectives has been closely related to a certain political positions and that this relation can explain the theoretical differences in these disciplines. To illustrate this, it is analysed a case study of the French context. It also argues about the advantages of the relational paradigm and explains how the inclusion of economics and sociology in this paradigm would allow their reunification, surpassing that pernicious gap. Also it exposes a sociological theory and an economic theory, which exemplify such unification.
\end{abstract}

Keywords: history of economic thought, economic sociology, heterodoxy, relational thinking, reflectivity, criticism.

JEL classification: B50, B52, B59, Z13.

* Fecha de recepción: 11/10/2012. Fecha de aprobación final: 23/07/2012.

** Profesor-investigador en el Departamento de Política y Sociedad de la División de Estudios Jurídicos y Sociales del Centro Universitario de la Ciénega, Universidad de Guadalajara, Jalisco, México. Correo electrónico: dr_sergiosandoval@yahoo.com.mx; sergio.sandoval@cuci.udg.mx.

El autor agradece a Carlos M. García González y Jesús Ruiz Flores sus valiosos comentarios, y a Beatriz A. Gallardo N. su ayuda en la corrección de estilo. No obstante, la versión final del texto es enteramente responsabilidad del autor. 
I believe the embeddedness argument to have very general applicability and to demonstrate not only that there is a place for sociologists in the study of economic life but that their perspective is urgently required there.

Mark Granovetter (1985)

\section{INTRODUCCIÓN}

El propósito de este artículo es contribuir a la reflexión acerca de la tesis de la unificación (o reunificación) de las ciencias sociales, particularmente de la sociología y la economía, así como de las razones por las que presumiblemente se ha dado el distanciamiento entre ellas. Según esa tesis, en algún momento de su proceso histórico de institucionalización y autonomía, estas ciencias habrían experimentado una divergencia entre ellas respecto de la forma en que conciben sus respectivos objetos de estudio, que acabaría no sólo por oponerlas, sino también por limitar su potencial explicativo. ${ }^{1}$ Se ha argumentado que tal distanciamiento tiene su origen y explicación en sus respectivas bases ontológicas y antropológicas, esto es, la forma como la economía y la sociología conciben a los seres humanos: una, esencialmente individualista; la otra, de naturaleza relacional (Tilly, 2000, p. 29 y ss.).

En efecto, la ciencia de la economía ha sido erróneamente identificada tout court con una perspectiva individualista, mientras que la sociología, con frecuencia, lo ha sido con una perspectiva relacional, pero ciertamente no se debe olvidar que ni toda la economía ha sido individualista, ni toda la sociología relacional. Sería más adecuado representarse el campo de las ciencias sociales como un continuum entre ambas perspectivas, en el que se pueden fijar posiciones más o menos inclinadas a una u otra, de manera relativamente independiente de asociaciones previas entre nombres propios de científicos, escuelas, teorías e incluso (o quizá principalmente) disciplinas enteras (como son los casos de la economía y la sociología). Al respecto se ha advertido que, de manera sorprendente, suele obviarse el hecho lógico de que la antítesis del individualismo no es la perspectiva relacional, sino el colectivismo, particularmente bajo la forma de una teoría de

\footnotetext{
${ }^{1}$ A esto se refiere Robert Boyer cuando afirma que "resulta evidente que la voluntad de construir una economía totalmente separada de las demás ciencias sociales - con excepción de la exportación de sus herramientas de análisis o de sus métodos-erosionó la pertinencia del análisis de los investigadores contemporáneos" (Boyer, 2010, p. 12). Una postura equivalente, pero referida a la sociología, es la de Pierre Bourdieu, como se ve más adelante en este mismo artículo.
} 
sistemas; visto así, el problema no se plantea sólo entre individualismo y colectivismo, sino entre una perspectiva substancialista y una relacional (Tilly, 2000, p. 31). ${ }^{2}$ Esta forma de ver las cosas puede explicar por qué algunas teorías pueden pasar por relacionales cuando en último análisis no lo son. ${ }^{3}$ El distanciamiento teorético entre la sociología y la economía se debería, pues, a un complejo error categorial (en el sentido de Ryle, 2005). Ahora bien, semejante error se debe en parte a una deficiente actitud reflexiva.

En efecto, quizás la propiedad más relevante del pensamiento relacional es su reflexividad, la cual puede ser definida como la "necesidad de orientar continuamente los instrumentos de las ciencias sociales hacia el investigador, en un esfuerzo por controlar mejor las distorsiones introducidas en la construcción del objeto" (Ghasarian, 2008, p. 252). ${ }^{4}$ Esto significa que una parte importante de la tarea de las ciencias sociales consiste en tomarse a sí mismas como objeto. ${ }^{5} \mathrm{El}$ ejercicio de la reflexividad puede adoptar innumerables formas, pero sin lugar a dudas una de las más contundentes es cuando su aplicación permite al propio razonamiento relacional demostrar su ventaja explicativa frente a otras perspectivas teóricas, como se trata de mostrar más adelante con el análisis de un caso práctico. ${ }^{6}$ De aquí que, en el resto de este texto, se prefiera la expresión compuesta "relacional-reflexiva" para hacer referencia a la perspectiva que se propone como alternativa a la individualista-substancialista.

${ }^{2}$ Si bien Tilly destaca el aspecto esencialista del individualismo, esto se debe al énfasis que pone en las "desigualdades categoriales". Hay que recordar que la esencia traduce, en el concepto, a la substancia.

${ }^{3}$ Tal puede ser el caso de la teoría de F. A. von Hayek (1958, p. 6 y ss.) sobre el "falso" y el "verdadero" individualismo. Otro ejemplo son las teorías del "capital social", que han gozado de cierto auge y que han servido para legitimar políticas de Estado, y que aunque parecen reconocer su importancia, en realidad implican una imagen muy deformada y parcial de las estructuras sociales (Marrero, 2006).

${ }^{4}$ Conviene advertir que esta concepción de la reflexividad no tiene nada que ver con la que ha popularizado George Soros (1999) en su discurso autolegitimador.

${ }^{5}$ El significado prístino del término "teoría" ( $\left.\theta \varepsilon \omega \rho \varepsilon ı v\right)$ está asociado a la noción de "punto de vista, perspectiva, enfoque". Así, una de las formas en que se ha expresado el pensamiento relacional y reflexivo es como análisis del "sistema de los puntos de vista" (Bourdieu, 1999b, p. 9). Como advierte Ghasarian: "La idea nietzscheana de una conciencia 'perspectivista', de acuerdo con la cual los 'hechos' son interpretaciones constituidas y todos los puntos de vista son subjetivos, tiene muchos puntos en común con la reflexividad crítica en las ciencias sociales” (Ghasarian, 2008, p. 251).

${ }^{6}$ Otra forma, no menos impresionante, es la que podría ensayar cualquier científico social al tomarse a sí mismo como objeto, tal y como hizo Pierre Bourdieu en su Esquisse pour une autoanalyse (Bourdieu, 2007). 
Empero, por útil que parezca este esquema, no explica por sí solo por qué la sociología y la economía llegaron a estar tan polarizadas y por qué eventualmente algunos teóricos, de ambas disciplinas, se han acercado más que otros a una u otra perspectiva. Semejante explicación tendría que provenir necesariamente del análisis histórico de las ciencias, aunque bajo una perspectiva determinada. Como ha señalado Fritz K. Ringer, al hablar de la historia social del conocimiento hay que desconfiar de la perspectiva "que sostiene que las ideas son causas incausadas" para adoptar, en cambio, una perspectiva relacional-reflexiva que tome en cuenta, no la influencia per se entre ideas o pensadores, sino el conjunto de posiciones y trayectorias de los productores de ideas en el campo intelectual o científico, así como sus luchas (simbólicas) por imponer determinadas ideas y la inmersión del campo intelectual o científico en una sociedad y una cultura dadas, además del grado de autonomía de dicho campo en relación con otros ámbitos, particularmente el del poder político (Ringer, 2010, pp. 197-200). De este modo, se estará en condiciones de señalar, si no el único, sí el más importante factor no científico de polarización en las ciencias sociales. Así pues, el primer continuum de lo individualista a lo relacional habría que combinarlo con otro definido por su mayor o menor autonomía en relación con la política (Lebaron, 1997).

En este trabajo partimos de dos supuestos, el primero de los cuales es que dicho factor no científico es de naturaleza estrictamente política, es decir: la adopción de una perspectiva más individualista o una perspectiva más relacional ha sido, al mismo tiempo, una opción epistemológica y política; sólo de esta manera se pueden explicar las divergencias teóricas en las ciencias sociales, particularmente en la sociología y la economía, no obstante que desde hace mucho los historiadores han advertido que el poder político ha representado una fuerza heterónoma frente a la cual estas ciencias han tenido que ir construyendo trabajosamente su autonomía teórica (Deane, 1993). ${ }^{7}$

La historia de la política y de la filosofía moral (Schneewind, 2009; Held, 2001) nos enseña que hay dos fuerzas antagónicas en cuya tensión se en-

\footnotetext{
${ }^{7}$ Lo cual no descarta la eventual coincidencia, nunca perfecta, de teóricos de inspiración relacional con posturas políticas que en última instancia fundan su legitimación en una visión poco relacional de la realidad económica y social. Es el caso de la tesis de la "tercera vía", cuyo autor, el sociólogo inglés Anthony Giddens, recibió de Pierre Bourdieu una de las más ásperas críticas: "consejero de comunicación del príncipe" lo llamó el sociólogo francés, así como "tránsfuga del mundo universitario al servicio de los dominantes, cuya misión es poner en términos académicos los proyectos políticos de la nueva nobleza del Estado y de la empresa" (Bourdieu y Wacquant, 2000).
} 
gendran las diferentes realizaciones del Estado como máxima institución social y que no sería posible reducir a ningún par de etiquetas o nombres. ${ }^{8}$ Lo que sí se puede decir es que corresponden a dos tendencias que difieren en su respuesta a la pregunta esencial sobre cuál debería ser la función del Estado respecto a la distribución de los bienes entre los individuos. En esta pregunta leemos, entre líneas, conceptos como "derechos", "justicia", "igualdad" y "democracia"; el problema es que cada uno de estos términos ha tenido un significado diferente para una $u$ otra postura o fuerza antagónica, aunque ambas los esgrimen constantemente. Como sea, se acepta que históricamente la ciencia económica se ha diferenciado y tornado autónoma de la economía política, lo mismo que la sociología de las "ciencias políticas" (Deane, 1993, p. 152). En realidad, la discusión de las relaciones entre los fines puramente cognoscitivos de las ciencias sociales y los fines puramente prácticos, cuya formulación más elocuente fue hecha por Max Weber en los textos que componen El político y el cientifico, de 1910 (y cuyo título se parafrasea en el del presente artículo), es un tema que está muy lejos de haber sido resuelto. ${ }^{9}$

El segundo supuesto puede ser mucho más polémico que el primero, ya que consiste en la idea de que la perspectiva relacional no sólo es epistemológicamente, sino también políticamente, más útil que la individualista. ${ }^{10}$ De hecho, no deberían sorprender sus ventajas explicativas, e incluso políticas, por dos simples razones, ambas de orden histórico y epistemológico: primero, porque la noción misma de ciencia social, sobre todo cuando pensamos en sociología, implica lógicamente no sólo a los individuos sino a las estructuras de las relaciones entre ellos, por lo tanto, tiende a una visión más comprensiva de toda la sociedad y, por ende, más afín a una concepción de lo político. Segundo, porque ya desde inicios del siglo XX, al menos los historiadores y filósofos de la ciencia (destacadamente Ernst Cassirer en Alemania y Gaston Bachelard en Francia) habían advertido que, en su evolución histórica, las ciencias en general, progresivamente y en lo

${ }^{8}$ Durante la historia han tenido varios nombres: conservadurismo y progresismo, derecha e izquierda, Antiguo Régimen y Nuevo Régimen, liberalismo y regulacionismo, dictadura y democracia, capitalismo y socialismo, pero al final todas estas etiquetas siempre han resultado ambiguas o imprecisas.

9 Así, por ejemplo, a pesar de las muchas afinidades (y amistad) entre Jean-Claude Passeron y Pierre Bourdieu, ellos siempre discreparon a este respecto (véase Passeron, 2003, pp. 34-35).

${ }^{10}$ Aunque no se comparte esta tesis como tal, parece que en este sentido iría la intuición de Von Hayek respecto de la relación entre lo que él llamó el "verdadero individualismo" y su concepto de "socialismo" (Hayek, 1958). 
fundamental, tienden a superar una fase substancialista y esencialista para adoptar formas relacionales. ${ }^{11}$

Pero, ¿en qué se funda esta utilidad política? Las ciencias sociales tienen por fin último elaborar una verdad científica acerca del mundo social, mientras que las ciencias políticas y la política misma constituyen un espacio de lucha también por la verdad sobre el mundo social, pero en constante tensión con la lucha por el poder, particularmente por el Estado y su capacidad de controlar la acumulación y redistribución de recursos de todo tipo. Es por esto que las ciencias sociales están constantemente influenciadas por las fuerzas políticas a través de innumerables mecanismos de poder temporal (por ejemplo, condicionar el financiamiento de la investigación a determinadas temáticas impuestas como "prioritarias"). Empero, es posible que conocimientos elaborados por las ciencias sociales funcionen como "ideas reguladoras" que orienten la práctica política, dada su construcción metódica, racional y factual (Bourdieu, 2002, pp. 9-10). Ya Weber había advertido esta coincidencia entre ciencia social y política, así como la necesidad de diferenciar entre buscar el conocimiento y la emisión de juicios sobre lo social (L'Estoile, 2003, p. 138). Ergo, se puede postular que la perspectiva relacional-reflexiva puede orientar mejor la práctica política porque explica mejor el mundo social.

Este esquema es del todo legítimo y de ninguna manera nos instala en una concepción idealista de la historia de las ideas, ni en un positivismo histórico radical, aunque ciertamente es de naturaleza estrictamente histórica. No se pretende, entonces, desarrollar una teoría epistemológica vacía de hechos históricos (esto es, deshistorizada) y aislada de las estructuras sociales, aunque tampoco parece fructífero reducirlo todo a las "condiciones históricas", obviando la especificidad de los procesos de producción científica. Cabe precisar que no se intenta llevar a cabo una minuciosa reconstrucción histórica de la génesis y evolución de la economía y la sociología - de hecho ni siquiera se ensaya un bosquejo-, sino solamente destacar algunos puntos clave de esa historia (con el auxilio de algunos autores) que permiten llegar a algunos planteamientos útiles. Por otro lado, es sabido que la historia social de las mismas ciencias sociales no se ha escrito completamente, por lo que se tiene que partir de lo que la historia y la sociología del conocimiento han logrado con tanto esfuerzo.

${ }^{11}$ Intuición que confirmarían, entre otros, Jean Piaget, Thomas S. Kuhn y Michel Foucault, cada uno a su manera. 


\section{ECONOMÍA Y SOCIOLOGÍA: LA POLÍTICA COMO PRINCIPIO HISTÓRICO DE DIFERENCIACIÓN}

El historiador Robert Darnton, en su brillante ensayo titulado Los filósofos podan el árbol del conocimiento: la estrategia epistemológica de la Enciclopedia, explica que la verdadera novedad de la Enciclopedia, obra cuyas peripecias históricas Darnton ha estudiado profundamente, radicaba no tanto en su contenido como en la "estrategia epistemológica" adoptada por sus célebres autores, es decir, la forma como clasificaron los conocimientos. La forma, como tal, tampoco era novedosa: se trataba de otra clasificación en "árbol" más, como tantas inspiradas en la obra de Porfirio, filósofo neoplatónico del siglo III d.C. Empero, en esa ocasión, "los enciclopedistas reconocieron que el conocimiento significaba poder, y al deslindar el mundo del conocimiento, se propusieron conquistarlo" (Darnton, 1987, p. 211). Es decir, al reorganizar la clasificación de los conocimientos de la época (subordinando la teología a la última rama o derivación posible, por ejemplo), se cifraba al mismo tiempo una postura política. Desde entonces, como advirtiera Foucault, la relación entre el conocimiento y el poder sería cada vez más estrecha, particularmente bajo la forma de economía política (Foucault, 1992).

Con el ascenso del capitalismo, como observó agudamente Max Weber, se fue consolidando un cuerpo de funcionarios, especialistas y científicos formados en las universidades, a la vez que el conocimiento técnico y científico se fue volviendo cada vez más útil y, por ende, más necesario. Actualmente, el sociólogo John B. Thompson ha advertido cómo los cambios en el mundo del trabajo en las sociedades industriales occidentales, el surgimiento del sector de servicios y de industrias dependientes del conocimiento, al igual que la revolución tecnológica y de las comunicaciones, transformaron el contexto social de la política. De la política partidista basada en las grandes doctrinas de reivindicaciones de las clases sociales ("política ideológica"), se pasó a una política basada en la confianza y la credibilidad ("política de la confianza") y ésta depende, cada vez más, de plataformas políticas apoyadas o legitimadas científicamente, particularmente por la economía (Thompson, 2003, p. 293). En última instancia, el papel original de los economistas como asesores o consejeros en materia de economía política, aun con su progresiva autonomía (Deane, 1993, p. 152-153), nunca ha desaparecido. Es por esto que se afirma que la naturaleza de las causas de las divergencias en las ciencias sociales, particularmente entre la sociología y la economía, es en 
gran medida política, aunque se exprese como un error categorial en el plano teórico.

Es bien sabido que, en orden de aparición histórica, la economía antecede a la sociología (Collins, 1996, p. 32), pero es menos conocido el proceso de aparición del pensamiento económico y la forma como se fue diferenciando del sociológico (Deane, 1993), desde Adam Smith, pasando por Marx, Pareto, Simmel, Veblen, hasta Weber, Sombart y Schumpeter (Giner, 2004). Como recordara alguna vez el economista estadunidense Kenneth E. Boulding (1970), Adam Smith fue un profesor de filosofía moral, y en esa fragua fue hecha la economía, de ahí que Smith, al igual de Bentham, la considerara la más moral de las ciencias. Históricamente, el aspecto "moral" fue paulatinamente relegado por la economía mientras que era profundizado por la sociología (así pasamos del concepto de división social del trabajo de Marx, al de división del trabajo social de Durkheim). Un momento clave en este proceso histórico de diferenciación de las disciplinas es el que corresponde al debate en la primera mitad del siglo XIX entre la economía "política" y la economía "social". La primera se interesaba en el valor estrictamente económico del trabajo, la producción y el mercado, mientras que la segunda se interesaba particularmente en las condiciones de la vida obrera. "Esta distinción no es únicamente el producto de una división del trabajo intelectual. Es el resultado, en lo esencial, de un conflicto político que a lo largo del siglo XIX no dejó de oponer" a la burguesía industrial (que accedía al poder político) y a la aristocracia conservadora (Lenoir, 1993, p. 57); esta oposición dio lugar a la noción de "problema social" y éste a su vez, replanteado científicamente, a la sociología, pasando por la exaltación weberiana de la economía como ciencia wertfrei ("libre de valores"), con la consecuente (y errónea) delegación exclusiva del estudio de "lo social" a la sociología (Lenoir, 1993, p. 58).

El advenimiento de las dos grandes guerras de la primera mitad del siglo XX significó un largo paréntesis en el desarrollo de la sociología autónoma. Después de la muerte de Durkheim en Francia y de Weber en Alemania, el epicentro de la sociología se movería a Estados Unidos dando origen a las teorizaciones de Talcott Parsons y Robert Merton, el interaccionismo, la fenomenología social y el metodologismo estadístico representado por Paul F. Lazarsfeld (Collins, 1996), y no será sino hasta la década de los sesenta que comenzarán a surgir nuevos grandes sistemas teóricos en Francia, Alemania e Inglaterra, principalmente, a partir de diversas corrientes de pensamiento filosófico, sociológico e incluso económico, que durante esos años subsistieron en la marginalidad tanto en Europa como en América. 
El caso francés resulta paradigmático al respecto y clave para nuestro análisis. De manera similar a la suerte que corriera la obra de Max Weber en Alemania, aunque más radical, a la muerte de Durkheim su pensamiento fue objeto de duros ataques y descalificaciones por parte de grupos ultranacionalistas y conservadores, en una suerte de "Restauración" del mundo intelectual, pero persistió bajo la forma de una modesta tradición de los etnólogos durkheimianos, entre los que destacó Marcel Mauss. La filosofía subjetivista tuvo ocasión de reinstalarse particularmente con Jean-Paul Sartre, quien dominaría el panorama intelectual hasta finales de los sesenta, cuando nuevas formas de filosofía y el resurgimiento de la sociología aparecieron en escena para desplazarlo. La nueva sociología francesa tuvo varias raíces: el encuentro de esa tradición etnológica durkheimiana y el marxismo con la teoría estructuralista, proveniente de la lingüística, con Claude Levi-Strauss; el redescubrimiento de una vertiente de la fenomenología alternativa a la de Sartre, representada por Maurice Merleau-Ponty (otra vertiente de la fenomenología fue la de Alfred Schütz, que daría frutos en Estados Unidos); la revaloración de la epistemología histórica por parte de Bachelard, Canguilhem y Veullemin, así como el surgimiento de la "nueva historia" inspirada por la noción de larga duración de Fernand Braudel. De esa oposición a la "ortodoxia universitaria" surgieron los nombres de Michel Foucault, Jacques Derrida y Pierre Bourdieu, entre muchos otros (Pinto, 2002, p. 15).

En cuanto a la ciencia económica, la década de los sesenta resultó también crucial; particularmente el Mayo del 68 fue un momento crítico en la subsiguiente dinámica del campo de los economistas en Francia. Como en otras naciones, después de la Segunda Guerra Mundial, la "reconstrucción" de Francia fue más bien una reestructuración en todos los órdenes, proceso en el cual ganarían hegemonía la definición de políticas de derecha y la instalación de una poderosa tecnocracia identificada con la ortodoxia neoclásica, en coexistencia con dos grandes tendencias "críticas" del capitalismo, una de inspiración católica y otra marxista.

Después del Mayo del 68, cada una de estas tendencias críticas sufrió una crisis: una en sus fundamentos religiosos, la otra en sus fundamentos ideológicos, para resurgir a mediados de los noventa como un "movimiento de economistas para salir del pensamiento único"; en esta configuración del campo de los economistas franceses, queda claro que las posturas científicas son al mismo tiempo posturas políticas y que instituciones e individuos se clasifican principalmente según ese doble criterio (Lebaron, 1997, pp. 21-25). Empero, lo más relevante es advertir que una parte de la economía francesa contemporánea "no 
ortodoxa" es también la más cercana a la sociología relacional-reflexiva, como se explica más adelante.

\section{EL GIRO HACIA LA PERSPECTIVA RELACIONAL-REFLEXIVA EN LAS CIENCIAS SOCIALES}

Así pues, arribamos a dos tesis, la primera de las cuales afirma que en la historia moderna determinadas formas de conocimiento científico han sido utilizadas en el campo del poder (político), mientras que la otra, implícita en la primera, afirma que la estructura de las relaciones entre las ciencias puede ser afectada o modificada por la relación entre ellas y el campo del poder. Así, se afirma que no sólo la diferenciación entre las disciplinas científicas de la economía y la sociología obedece a un principio político, sino también la relativa subordinación fáctica de la segunda respecto de la primera: la economía, o mejor dicho, ciertas formas de teoría económica, suelen detentar un poder temporal respecto del resto de las ciencias sociales. ${ }^{12}$

Aquí se utiliza la noción de "poder temporal" en el sentido que lo entendía Pierre Bourdieu; éste, al estudiar las relaciones de fuerza o dominación en los campos de producción cultural (particularmente en el mundo académico-científico), identificó a aquellos agentes e instituciones que casi siempre, debido a una relación de subordinación y heteronomía con el poder político y/o económico, ocupan posiciones dominantes al interior de los campos, pero que generalmente poseen un capital específico (capital propiamente científico) endeble. En el otro extremo, estarían los agentes e instituciones con un gran capital científico que, al ser ampliamente reconocido como legítimo por la comunidad de sabios, opera como un capital simbólico "trascendente", por ejemplo, cuando una teoría adquiere el nombre de su creador (Bourdieu, 1999a; 2008). Se debe reconocer, empero, que aunque el servicio de legitimación científica de la política es más claro en el caso de la economía (en tanto "economía política"), también lo ha realizado la sociología (por ejemplo, la tesis de "la tercera vía" o la "teoría del capital social").

Ahora bien, no se puede dejar de hacer notar lo siguiente: en la medida en que la teoría social se aleja de los modelos esencialistas e individualistas y se

\footnotetext{
${ }^{12}$ La Real Academia Sueca de Ciencias a partir de 1995 decidió incluir también a la sociología y otras disciplinas en el Nobel de Economía, sin embargo, sólo reconoce las contribuciones de dichas ciencias a la economía.
} 
convierte o se complementa con una perspectiva relacional y comprensiva (reflexiva), no sólo ofrece mejores explicaciones de la vida social, sino que gana más en autonomía. Aunque los casos históricos de heteronomía en la ciencia suelen tomarse de regímenes totalitarios (tal es el caso de la doctrina Jdanov (o Zhadánov) en la Unión Sovietica), la vulneración de su autonomía ha adoptado diversas formas en otros países y épocas (Sandoval, 2011). Así como antes se advirtió que no toda la economía ha sido individualista (substancialista) ni toda la sociología relacional, también hay que precisar que dentro de la economía han existido innumerables escuelas y teorías que han manifestado una gran autonomía respecto de los poderes constituidos.

Basta con revisar someramente las teorías clásicas para constatar que hubo en ellas muchas intuiciones que fueron luego olvidadas o relegadas. Se ha notado en este sentido, el papel de los marcos institucionales (particularmente el referido al Estado), que ya había sido advertido por los clásicos (Marengo y Pasquali, 2009, p. 79; Gandlgruber, 2010, p. 16) pero que ha permanecido como una forma de análisis menor, marginada de las grandes corrientes. Charles Tilly tenía muy claro que el mismo Adam Smith consideró en sus análisis del mercado las condiciones sociales estructurales o institucionales, tales como las categorías clasificatorias de los grupos sociales, pero señaló que "la revolución neoclásica [...] desvió la atención económica de las categorías para centrarla en los individuos y los mercados [...]. El paso centenario de las ciencias económicas desde las descripciones relacionales hasta las individualistas simplificó el trabajo de los analistas, al precio de la pérdida de la verosimilitud" (Tilly, 2000, pp. 42-44). La historia de la disciplina está pletórica de casos. Por ejemplo: "John R. Commons (1934), injustamente ignorado, insistió hace sesenta años en que la ciencia económica debía comenzar sus análisis con las transacciones, no con los individuos. Los economistas, desgraciadamente, no le hicieron caso [...]. El análisis con fuerte énfasis en lo relacional sigue siendo un movimiento minoritario en el conjunto de las ciencias sociales" (Tilly, 2000, p. 31).

Sin embargo, las teorías prevalecientes en economía no pueden dejar de hacer referencia a lo que denominamos, con Charles Tilly y Pierre Bourdieu, una concepción relacional (Tilly, 2000, pp. 33-34; Bourdieu y Wacquant, 2005). Así, por ejemplo, en 1991 Ronald Coase recibe el Nobel por su descubrimiento y clarificación del significado de los "costos de transacción" y los derechos de propiedad para la estructura institucional y el funcionamiento de los mercados. En realidad, existe un gran número de corrientes o escuelas económicas reconocidas que de una u otra forma adoptan una perspectiva relacional, pero que tratan de 
diferenciarse de las teorías predominantes y se clasifican como alternativas heterodoxas (Gandlgruber, 2010).

Sobre todo después de la crisis de 2008, se incrementa el interés por esas otras formas de pensamiento económico. Como ha dicho el economista de la escuela regulacionista francesa, Robert Boyer, "es una buena oportunidad para presentar la macroeconomía de inspiración regulacionista", la cual, entre otras características, asume que "no se puede concebir una teoría económica pura, porque las esferas sociales, políticas y económicas se mezclan en la construcción de las formas institucionales y sus transformaciones. De hecho, la macroeconomía regulacionista es parte de un programa de investigación en términos de economía política en el sentido de los grandes autores clásicos" (Boyer, 2010). Esto es, la clave de esta escuela es que adopta una perspectiva sistemáticamente relacional de los fenómenos económicos y sociales.

Ahora bien, tomar en consideración en nuestro análisis a este representante de la economía regulacionista tiene un sentido preciso, pues es un claro ejemplo de acercamiento con el campo de la sociología, particularmente con la desarrollada por Pierre Bourdieu.

El mismo Boyer sostiene que las correspondencias entre la sociología de Bourdieu y las investigaciones inspiradas en la teoría de la regulación son sorprendentes, a pesar de las diferencias entre sus respectivos objetivos y nociones básicas (Boyer, 2003b).

Es, entonces, la adopción de una perspectiva epistemológica relacional en lo que consiste la ventaja del regulacionismo económico y, al mismo tiempo, lo que le permite establecer lazos de colaboración con la sociología, sin que ninguna de las dos ciencias se confunda con la otra. En este artículo se considera que la postura teórica más acabada en ese sentido está representada por la sociología de Pierre Bourdieu. Se podría afirmar que no sólo es un referente indispensable, sino que representa en un paradigma alternativo, como se muestra más adelante. $^{13}$

${ }^{13}$ Los conocedores del pensamiento de P. Bourdieu advertirán que éste llegó a denominarlo como constructivist structuralism o bien structuralist constructivism (Bourdieu, 1993, p. 127), lo cual es del todo coherente con lo que el mismo sociólogo denominó explícitamente "pensamiento relacional" (Bourdieu y Wacquant, 2005, p. 319). Afirmaba que "el aporte principal de lo que bien puede llamarse la revolución estructuralista ha consistido en aplicar al mundo social un modo de pensamiento relacional, que es el de la matemática y la física modernas y que identifica lo real no con substancias sino con relaciones" (Bourdieu, 1993, p. 129, sin cursivas en el original). 


\section{UNA SOCIOLOGÍA ECONÓMICA RELACIONAL Y REFLEXIVA}

Con sus investigaciones en la entonces colonia francesa de Argelia, a finales de los años cincuenta y principios de los sesenta, surgieron las primeras formulaciones que hizo Bourdieu de su crítica a las teorías económicas neoclásicas $\mathrm{y}$, en general, a toda forma de teoría en ciencias sociales que omita en sus fundamentos las dimensiones histórica y relacional de sus objetos. Analizó la paulatina incorporación de los argelinos, acostumbrados a una economía y una sociedad tradicionales agrarias, a una economía y unos mercados laborales regidos por la lógica capitalista (Bourdieu, 2006). Después de casi cuatro décadas de intenso trabajo, durante los cuales sometió a rigurosos análisis una gran diversidad de temas, Pierre Bourdieu concentró en un solo volumen su crítica a la teoría económica dominante. Dio a este libro el provocador título de Las estructuras sociales de la economía (Bourdieu, 2001).

Sostuvo que para comprender realmente las acciones e instituciones económicas, es necesario "construir modelos históricos capaces de dar cuenta con rigor y parsimonia de las acciones e instituciones económicas tal como ellas se dan a la observación empírica", pues "el mundo social está enteramente presente en cada acción económica". Según esto, la teoría económica que critica parte de una "amnesia de la génesis" del campo económico mismo y, por ende, también de las predisposiciones económicas de los agentes de la historia colectiva que se reproduce en las biografías individuales, lo que hace aparecer a los fenómenos económicos como universales, naturales y ahistóricos. Para la construcción de su objeto, esta teoría económica parte, pues, de una ruptura social tácita o implícita y de una abstracción de la práctica real; confunde, parafraseando a Marx, "las cosas de la lógica con la lógica de las cosas" (Bourdieu, 2001, pp. 13-19).

En frontal oposición con los presupuestos del individualismo metodológico y de las teorías de la decisión racional, Bourdieu afirmó que los sujetos inmersos en un campo económico actúan y piensan de manera "conforme" a la racionalidad económica, sin que necesariamente "tengan la razón por principio". Proponía, entonces, construir una "economía de las prácticas económicas" que tendría su principio en las predisposiciones aprendidas por los agentes en virtud de una larga exposición a las regularidades de la economía, a partir de las cuales se producen prácticas no necesariamente "racionales", sino "razonables", esto es, orientadas por el "sentido práctico" de estrategias (no teóricas y "cómodas") "adaptadas a las exigencias y urgencias de la acción" (Bourdieu, 2001, pp. 20-21). Dicho sea de paso, esto es lo que explicaría los resultados de numerosos estudios 
históricos y experimentales que demuestran que la exposición prolongada y sistemática a la racionalidad económica tampoco garantiza totalmente que los agentes (por ejemplo, expertos financieros) actúen totalmente de acuerdo a ella (Viale, 2009).

El error del economicismo o de la "economía económica", que consiste en universalizar, naturalizar y deshistorizar los fenómenos económicos (lo que da lugar a la creencia en el homo ceconomicus como individuo racional, interesado y egoísta), tiene su origen, según Bourdieu, en las mismas condiciones de producción de la teoría económica y constituye una variante de un "error intelectualista" o error de percepción propio de los mundos "escolásticos". Para que el trabajo intelectual fuera posible, explica, los sabios debieron gozar de las condiciones adecuadas para ello, esto es, sustraerse de las urgencias y las necesidades mundanas; para ello, se precisaron de ciertas condiciones económicas, materiales y sociales que aseguraran la posibilidad de la actividad intelectual (lo que Aristóteles denominó la skolé). Con la evolución de los mundos "escolásticos" (filosofía, teología, ciencias, artes, etcétera), la conciencia de esta originaria y necesaria toma de distancia con el mundo, objetivamente una relación privilegiada con el mundo, llegó a ser obviada u olvidada en virtud de una represión inconsciente (en sentido freudiano), que se ha manifestado en el pensamiento teórico principalmente bajo la forma de una atribución del punto de vista escolástico al mundo y al común de los individuos (Bourdieu, 1999a, p. 41 y 252-265).

Éste sería precisamente el error de la teoría económica dominante en la actualidad: que se proyectan artificialmente en la mente de los individuos los esquemas abstractos (definidos como "racionales") que el economista ha debido construir para tratar de explicar el mundo económico, lo que constituye una verdadera petición de principio. En consecuencia, el reto del economista sería, como apunta Charles Tilly en consonancia con Bourdieu, al menos de inicio, "bosquejar un modelo que ponga de relieve rasgos destacados de su objeto, pero que nunca se confunda con la realidad" (Tilly, 2000, pp. 41-42). Partiendo de esta crítica de la filosofía del agente, de la acción, del tiempo y del mundo social que sustenta las teorías económicas dominantes, y tratando de elaborar una mejor definición de la "razón económica", Pierre Bourdieu se dio a la tarea de expresar los principios de lo que él llamó una "antropología económica" (Bourdieu, 2001, pp. 219-252), que se tratará de enunciar sintéticamente en seguida.

Para realizar sus análisis, Bourdieu partió de una teoría del espacio social que tenía como propósito realizar una ruptura con las nociones preconstruidas de "sociedad" comúnmente utilizadas. En lugar de empezar, de manera 
irreflexiva y acrítica, presuponiendo una idea determinada de "sociedad", comenzó con el concepto altamente abstracto de espacio social, al cual definió como una estructura de yuxtaposición de posiciones sociales (identificadas con individuos o, por ejemplo, instituciones), que a su vez se definen como "posiciones en la estructura de la distribución de las diferentes especies de capital" (Bourdieu, 1999a, p. 178). En este espacio se pueden diferenciar, a su vez, configuraciones o ámbitos específicos de relaciones entre agentes o instituciones (que pueden ser empresas) en los que están en juego diversas formas específicas de capital (económico, cultural, científico, político, simbólico, etcétera). Estos ámbitos son denominados campos y de alguna manera se corresponden con ámbitos o esferas de la vida social reconocidos (arte, ciencia, política, religión, sistema económico, deporte, etcétera) y sus respectivas instituciones (academias, institutos, estados, partidos, iglesias, empresas, clubes, etcétera) y agentes (artistas, científicos, políticos, clérigos, empresarios, financieros, deportistas, etcétera). Éstos, en virtud de su mayor o menor autonomía respecto del espacio social y otros campos, poseen sus propias "reglas del juego", sus propias luchas y objetos de lucha. ${ }^{14}$

El campo económico es, pues, un campo entre otros. Son las empresas, que actúan como agentes, y sus relaciones mutuas, las que lo crean, son "fuentes generadoras de campo" pero que, al mismo tiempo, están definidas por su posición en éste y por el volumen y estructura de sus diferentes tipos de capital: financiero (real o potencial), cultural (que se compone de capitales tecnológico, jurídico y organizativo e informativo), comercial, social y simbólico (entendido como "crédito" o confianza en la firma). Es la distribución de todas estas propiedades la que determina la estructura del campo en cada lugar y momento histórico considerados en un análisis económico dado. Y es también lo que determina el mercado y la formación de precios: "No son los precios los que hacen todo, sino el todo el que hace los precios" (Bourdieu, 2001, p. 225).

Esto último se debe a que, ciertamente en última instancia, las decisiones económicas están determinadas por el campo. El verdadero sujeto de la economía es el campo económico mismo y no un hipotético homo ceconomicus. El principio fundamental es que la razón económica es la expresión de la relación

\footnotetext{
${ }^{14}$ Uno de los instrumentos de análisis de los campos usados por Bourdieu fue el análisis factorial de correspondencias múltiples, desarrollado por el matemático francolibanés Jean-Paul Benzecri en los sesenta y que vino a resolver problemas de análisis estadístico enfrentados por el propio Bourdieu en los mismos años, por ejemplo, en Bourdieu y Darbel (2003). Para un análisis detallado del papel de las estadísticas en la sociología de Bourdieu y su relación con la econometría y la demografía, véase Desrosières (2003).
} 
entre un habitus y un campo, esto es, entre un sistema de predisposiciones socialmente constituidas en relación con un campo (económico), y las estructuras objetivas de ese campo, también socialmente constituidas. La noción de habitus es el recurso teórico que precisamente permite superar la noción ortodoxa de homo ceconomicus como individuo racional-utilitario, la cual se revela entonces como una "ilusión bien fundada" (como decía Durkheim): constituye una "hipótesis irrealista" que puede parecer convalidada porque "en razón de la correspondencia estadística, empíricamente establecida, entre las predisposiciones y las posiciones [en el espacio social], los agentes forman [...] esperanzas razonables, es decir, ajustadas a las posibilidades objetivas, y casi siempre controladas y reforzadas" directamente por controles colectivos (Bourdieu, 2001, p. 242). Empero, muy al contrario de lo que pudiera pensarse, el habitus no es un principio de reproducción perfecta o de inmovilismo histórico: todo lo contrario, debido a la enorme complejidad y dinamismo del campo económico, es un principio de cambio y transformación (Boyer, 2003a, p. 275). De hecho, estos conceptos han sido aplicados con éxito al estudio de la historia del mundo de las empresas (Fridenson, 2003).

A partir de estos principios es que Bourdieu llegó a proponer una "integración" o "hibridación” de la sociología y la economía. Recordó lo arbitrario de la distinción fundamental "entre el orden de lo económico, regido por la lógica eficiente del mercado y destinado a las conductas lógicas, y el orden incierto de lo 'social', habitado por la arbitrariedad 'no lógica' de la costumbre, las pasiones y los poderes", para imaginar la reunificación de una ciencia social artificialmente dividida. Empero, advierte, "esta ciencia social reunificada, capaz de construir modelos de los que ya no se sabrá si son económicos o sociológicos, tendrá sin duda muchas dificultades para imponerse, a la vez por razones políticas y por razones que obedecen a la lógica propia de los universos científicos" (Bourdieu, 2001, pp. 237-238).

Si bien la sociología de Bourdieu ha sido objeto de críticas y descalificaciones por parte de los propios sociólogos a causa del uso que hace de la analogía económica (Lebaron, 2007, pp. 84-85), es posible convencerlos de la pertinencia y utilidad de esta opción teórica cuando se explica que "la dimensión simbólica de las realidades sociales se vuelve el instrumento, que deriva de la tradición durkheimiana, que permite a Bourdieu mantener constantemente un punto de vista radicalmente sociológico en su esfuerzo por generalizar un discurso económico que no sea ya puramente económico" en virtud del "doble movimiento de economización formal de su análisis del orden simbólico y de 
interpretación simbólica de los fundamentos de la realidad económica" (Lebaron, 2007, p. 94).

No obstante, puede resultar aún más difícil convencer a los propios economistas, máxime porque la economía ha ganado prestigio en el mundo contemporáneo, tanto científica como políticamente, amén de la relación históricamente conflictiva con la sociología, con la que se disputa la verdad legítima del mundo social. Los economistas pueden rechazar la propuesta de la sociología económica en virtud del divorcio aparentemente irreconciliable entre estas disciplinas, debido a la mutua ignorancia, ya sea activa (es decir, porque se teme que su reconciliación conlleve la pérdida de privilegios, reales o imaginarios, pecuniarios o simbólicos, para ambas partes) o pasiva (debido al "tribalismo académico"). Y cuando se logren pasar las fronteras, quizá porque ya es inevitable, entonces esta sociología deberá librar su batalla también en el mismo territorio que la economía, y como en toda batalla (abusando quizá de la metáfora), tendrá aliados y adversarios. Pero, a diferencia de las guerras en las que se gana por el argumento de la fuerza, en el campo científico la batalla se debe ganar por la fuerza del argumento. En lo que a este artículo concierne, se propone la sociología económica de Pierre Bourdieu como referente clave para progresar en la solución del error categorial fundamental, asociado a los vaivenes políticos, y así contribuir a la reunificación de las ciencias sociales.

\section{EL SOCIÓLOGO, EL ECONOMISTA Y LOS CAMPOS CIENTÍFICOS. UN CASO PRÁCTICO}

Sin lugar a dudas, la mejor manera de ilustrar las ideas antes desarrolladas será recurrir a un caso práctico. En seguida se expondrá, pues, la crítica que el economista francés Olivier Favereau ha dirigido a la sociología de Pierre Bourdieu (Favereau, 2005). A riesgo de simplificar demasiado, se puede decir que según Favereau la sociología de Bourdieu es análoga a la economía ortodoxa, a pesar de que pretende criticarla; de acuerdo con esto, mientras que Bourdieu creía haber construido sus teorías contra la economía neoclásica, en realidad están construidas de manera que solamente podrían ser una crítica contra el modelo clásico, y esto de manera análoga a la crítica que hiciera la economía neoclásica, desdeñando o ignorando los avances de la economía que Favereau llama "heterodoxa". La sociología de Bourdieu reflejaría "literalmente", dice Favereau, "una $\mathrm{u}$ otra versión de la ortodoxia económica $[. .$.$] en una forma invertida, como en$ un espejo", lo cual, según él, explicaría simultáneamente "semejanzas formales 
y divergencias aparentes" entre la sociología económica de Bourdieu y la economía neoclásica (Favereau, 2005, p. 317). Así, la sociología de Bourdieu constituiría una "ortodoxia alternativa" y no una alternativa a la ortodoxia.

En conclusión, Favereau cree defender una postura teórica totalmente ajena a las posturas ortodoxas codificadas en la analogía entre las "fallas de reproducción" (Bourdieu) y las "fallas de coordinación" (economía ortodoxa) y sostiene que, en ambos campos teóricos, el problema es que se parte de "un modelo de individuo perfectamente ajustado y, por ende, exclusivamente dedicado a su modelo de orden colectivo", por lo que haría falta "una nueva concepción del individuo, intérprete y no solamente calculador, capaz de tener posiciones éticas y realizar juicios críticos", más "democrático"; y las ciencias sociales deberían "centrarse en los fenómenos de coordinación parcial, que volverían a llevar a la teoría económica a la senda del realismo cognoscitivo/colectivo, y los de reproducción parcial, que permitirían discriminar entre dinámicas de aprendizaje colectivo más o menos democráticas" (Favereau, 2005, p. 359). Y decimos que Favereau cree defender una postura del todo diferente a las dos "ortodoxias", por varias razones.

Primero, habría que tomar en cuenta la lectura que Robert Boyer hace de la obra de Bourdieu. Boyer (2003a, 2003b) se ha referido explícitamente al texto de Favereau como uno entre otros cuyos autores lamentablemente han realizado una lectura apresurada y parcial de la obra de Bourdieu: "Un análisis más atento, y fiel a la letra como al espíritu, abre muchas otras perspectivas" (Boyer, 2003b, p.65), pues la "declinación" o "transposición" sociológica de ciertas nociones clave de la economía (capital, mercado, interés, etc.) si bien resultan muy útiles, hacen correr a Bourdieu el riesgo de incomprensión por parte de los economistas. Empero, al parecer el sociólogo asumió dicho riesgo pues, "practica así el equivalente del arte del judoca: importar una noción clave en el análisis dominante de las sociedades contemporáneas para mejor hacer surgir la lógica de las interacciones en el seno de un campo". Como sea, concluye Boyer, tomar la teoría de Bourdieu "por una variante de la teoría neoclásica estándar [...] sería omitir sus numerosos aportes" a la economía (Boyer, 2003a, p. 270), particularmente a la economía "institucionalista" y, más puntualmente, a la escuela regulacionista (Boyer, 2003b, p. 73). Cabe destacar que Boyer no hace todas estas afirmaciones en el vacío, sino a partir de un análisis minucioso de la evolución de la obra de Bourdieu, además de su propia experiencia como economista, explicando cómo el cambio o transformación social tiene un lugar central en la obra del sociólogo, a diferencia de lo que Favereau cree. "Le concept d'habitus, 
que d'incompréhensions!" (El concepto de habitus, ¡cuántas incomprensiones!), exclama Boyer (2003a, p. 273).

En segundo lugar, no se puede pasar por alto que la crítica que hace $\mathrm{Fa}$ vereau, en tanto teoría, puede ser del todo explicada por un análisis del campo de los economistas franceses iprecisamente bajo la lupa de la sociología de Pierre Bourdieu! En efecto, cuando afirma Favereau que "un economista heterodoxo no se reconoce en el cuadro que pinta Pierre Bourdieu de su comunidad profesional" (Favereau, 2005, pp. 312-313), en realidad no está adoptando un punto de vista comprensivo de esa comunidad, cosa que sí lleva a cabo Boyer (2003b, p. 68), sino más bien está hablando de un punto de vista entre otros, desde su particular posición y condición en esa comunidad. Ahora bien, esta comunidad se puede analizar precisamente como un campo social, el campo de los economistas.

Toca al economista devenido sociólogo de la escuela de Bourdieu, Frédéric Lebaron, este análisis, en su revelador artículo titulado "La dénégation $d u$ pouvoir. Le champ des économistes français au milieu des années 1990" (La denegación del poder: el campo de los economistas franceses a mediados de los noventa) (Lebaron, 1997). En este artículo, Lebaron explica la génesis y estructura de lo que Favereau llama la "comunidad profesional" de los economistas, es decir, en lenguaje sociológico, el campo de esa profesión. Así, aplicando la teoría de los campos sociales, Lebaron describe "una débil autonomía del campo, la jerarquía de las dotaciones sociales, la oposición entre poder espiritual y técnico y poder político y económico" y explica que "apoyándose en la exploración de esta estructura y de sus relaciones de fuerza, que se traducen en formas de consagración específicas, se puede en efecto dar cuenta del principio de las tomas de posición científicas y políticas de los economistas que reside en el espacio de sus relaciones objetivas" (Lebaron, 1997, p. 5). Es en este sentido que afirmamos que el texto de Favereau expresa perfectamente su posición en el campo.

En la gráfica 1 se muestra un diagrama elaborado a partir del texto y del diagrama original construido por Lebaron con base en un análisis estadístico de correspondencias múltiples, tomando en cuenta las propiedades pertinentes de los individuos (Lebaron, 1997, p. 10). En esta gráfica se ubican claramente las posiciones de Boyer y Favereau en el campo: como se puede observar, son más bien opuestas, pues el cuadrante derecho corresponde a las posiciones dominantes en el campo profesional, mientras que en el izquierdo están las dominadas. Con más precisión: "Las elecciones teóricas aparentemente más alejadas pueden obedecer, en el campo de los economistas, a lógicas homólogas bastante inconscientes, como la oposición entre una economía orientada a la investigación y una economía 
Gráfica 1. El campo de los economistas franceses a mediados de los años noventa (con base en Lebaron, 1997, p. 10)

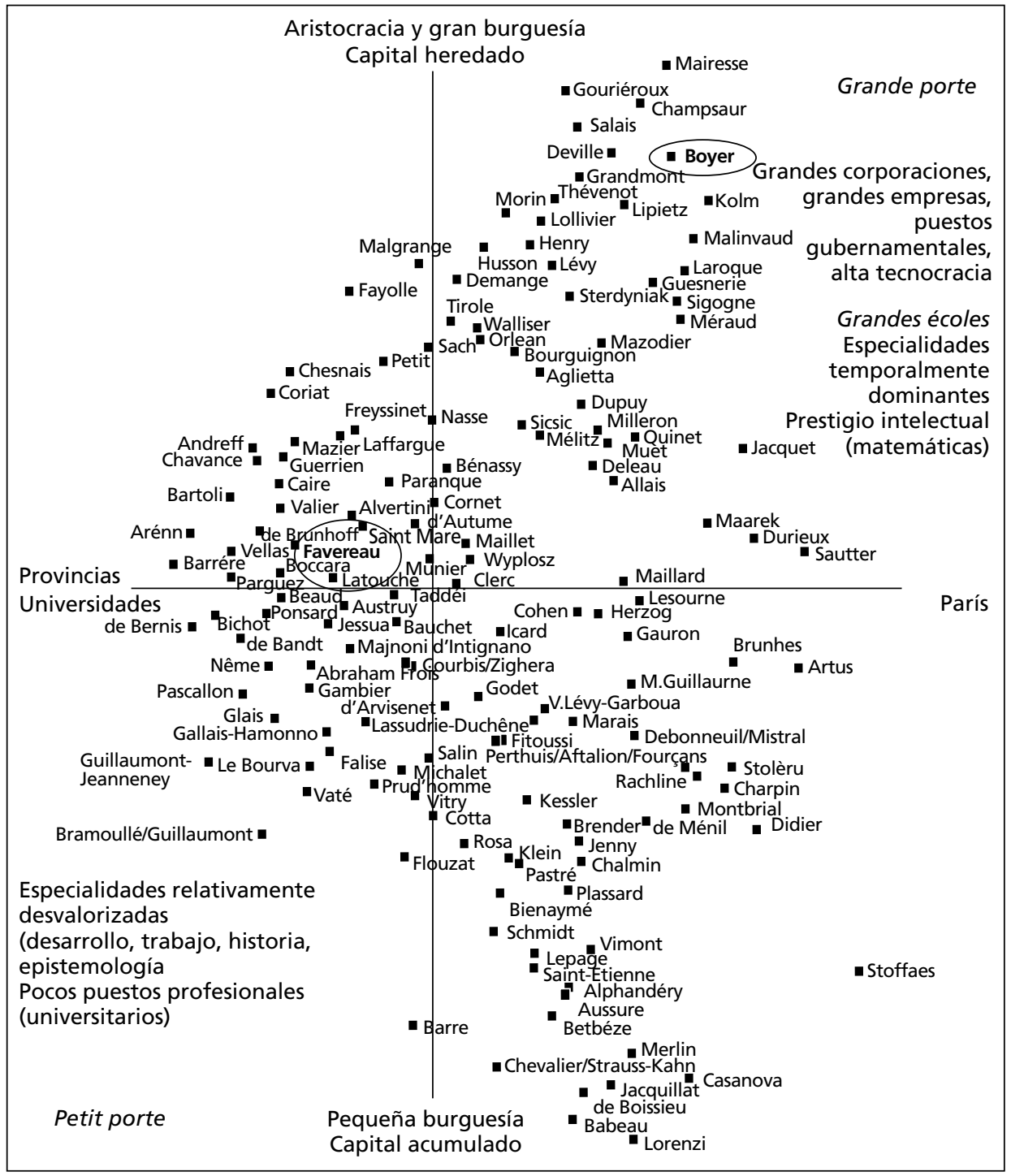

aplicada a la decisión burocrática y política: los neoclásicos (sobre todo los más matemáticos) y los economistas críticos con más diplomas, a menudo salidos de las grandes écoles [instituciones de educación pública superior de alto nivel, en Francia], pueden oponerse a los economistas del poder sin concordar, empero, científica y políticamente" (Lebaron, 1997, pp. 17 y 19). 
De este modo, los poderes intelectual y técnico, así como los poderes político y económico, pueden coincidir en ese espacio sin que sus tomas de posición teóricas y políticas coincidan: al igual que Boyer, regulacionista e institucionalista, "los economistas 'neoclásicos' más prestigiosos, el primero de entre ellos Edmond Malinvaud (antiguo director de la Previsión, antiguo director general del Institut National de la Statistique et des Études Économiques (INSEE), director de estudios honorario en la École des Hautes Études en Sciences Sociales (EHESS) y profesor en el Collège de France), están igualmente situados en este polo del campo [y] deben al menos una parte de su notoriedad a sus publicaciones en importantes revistas americanas [...] autoridad científica y experiencia burocrática" (Lebaron, 1997, pp. 13 y 16).

Al menos en ese artículo, empero, Lebaron no proporciona datos precisos de los individuos analizados, así que se ha realizado una sencilla búsqueda por cuenta propia de los respectivos currículos de Favereau y de Boyer.

Olivier Favereau: profesor universitario, de origen pequeñoburgués, de provincias, formado por una universidad y no por una grande école, carrera profesional limitada como profesor (investigación académica), con algunas participaciones en grupos técnicos y comisiones (Ministerio de Educación), cultiva la economía del trabajo y la "social" que, al menos a finales del siglo Xx, eran especialidades subordinadas. Ingresó al campo por la agregation profesoral y una trayectoria de larga duración (la petite porte), y no por la consagración debida a la relevancia de su obra o actividad profesional. En conclusión, Favereau ocupa una posición "dominada" en el campo de los economistas franceses.

Robert Boyer: fuerte autoridad intelectual, representante de la escuela de la regulación, director de investigación en el Centre National de la Recherche Scientifique (CNRS) y director de estudios en la EHESS, cercano a las teorías marxista y neokeynesiana, abierto a las demás ciencias sociales (la grande porte). En conclusión, Boyer ocupa una posición "dominante" en el campo de los economistas franceses; como intelectual, habría que decir que Boyer, con Bourdieu, tiene una posición homóloga a "la fracción dominada de la clase dominante" y según los propios análisis de Bourdieu (2008), esta posición sería también homóloga a la de los sociólogos en general. No resulta extraño, pues, que Boyer publique en la revista fundada por Bourdieu (Actes de la recherche en sciences sociales) y que coincida en lo fundamental con éste en lo que respecta a su "antropología económica" (Boyer, 2003b). "En el polo intelectual, los agentes están relativamente desprovistos de poderes de decisión propiamente económicos y están, 
en revancha, dotados de una autoridad fundada sobre su obra, sus investigaciones. Ejemplar de esta posición, Robert Boyer" (Lebaron, 1997, p. 13).

Ahora bien, recordando que "las posiciones [en el campo de los economistas] condicionan, en un doble movimiento, la lógica de las elecciones científicas y la de las inclinaciones propiamente políticas" aunque "es la posición en el campo la que funda con más seguridad las tomas de posición políticas y no a la inversa" (Lebaron, 1997, p. 19), debemos concluir que el análisis de Favereau no podía escapar a estas determinaciones. En efecto, según el estudio de Lebaron, y nuestras propias inferencias, Favereau no estaría tanto debatiendo con Bourdieu como con Boyer o, mejor dicho, con la fracción de economistas dominantes y esto desde su postura doblemente dominada en el campo (temporal e intelectualmente), autodenominada como "heterodoxia económica", todo lo cual explica su lectura de Bourdieu, inevitablemente deformada, o filtrada, por su posición en el campo; su crítica es más bien académica (teoricista, alejada tanto del ámbito empírico como de la argumentación matemática) y claramente inclinada hacia el discurso político. ${ }^{15}$

Esto explica muy bien el interés por identificar la sociología de Bourdieu con la economía ortodoxa o estándar, lo que de hecho cree lograr al tomar a cada una como la imagen especular de la otra, única forma en que puede, dada su posición en el campo, entender la tesis de Bourdieu de la economía inversa de los bienes simbólicos: "El desafío que las economías fundadas sobre la denegación de lo 'económico' plantean a cualquier clase de economicismo reside precisamente en el hecho de que sólo funcionan y pueden funcionar en la práctica -y no únicamente en las representaciones- al precio de un rechazo constante y colectivo del interés propiamente 'económico' y de la verdad de las prácticas que el análisis 'económico'devela" (Bourdieu, 2010, p. 153, sin cursivas en el original). ¿No es acaso esto lo que Favereau concibe como "fenómenos de coordinación parcial, que volverían a llevar a la teoría económica a la senda del realismo cognoscitivo/colectivo, y los de reproducción parcial, que permitirían discriminar entre dinámicas de aprendizaje colectivo más o menos democráticas"? (Favereau, 2005, p. 359). Y cuando Bourdieu afirma que "el comercio de arte, comercio de las cosas en las que no hay comercio, pertenece a la clase de prácticas en las que sobrevive la lógica de economía precapitalista" (Bourdieu, 2010, p. 153) ¿no es también equivalente el artista, por ejemplo, al "individuo, intér-

${ }^{15} \mathrm{Y}$, al respecto, haría falta analizar la forma específica del capital politico que representan estas tomas de posición políticas, particularmente bajo la forma de un "capital militante" (Poupeau, 2007, p. 39). 
prete y no solamente calculador" que permitiría "ensanchar las lagunas de la reproducción (lejos de legitimar las relaciones de fuerza capitalistas)" que Favereau concibe?

Ahora bien, a pesar de todo lo anteriormente explicado, se podría sostener que la principal causa de la lectura "negligente" que Favereau hace de la sociología económica de Bourdieu, obedece al carácter estrictamente teoricista de su argumentación, esto es, que no considera las ventajas explicativas de esa sociología cuando ha tratado con objetos empíricos "situados y fechados", cosa que, hay que insistir, Boyer sí toma en cuenta. Al parecer, aunque de una manera muy elaborada, Favereau cae en la típica lectura deformada de la teoría, que consiste, básicamente, en practicar una especie de reducción de los conceptos que opera, necesariamente, aislando a los conceptos del sistema conceptual completo. A fin de cuentas, se trata del viejo truco (falacia) del "hombre de paja": reducir al oponente a una caricatura contra la cual es fácil arremeter. Por esto, hace ya muchos años, Bourdieu y sus colegas establecieron la distinción entre conceptos "operatorios" y "sistemáticos":

"Al rigor analítico y formal de los conceptos llamados 'operatorios' se opone el rigor sintético y real de los conceptos que se han llamado 'sistemáticos' porque su utilización supone la referencia permanente al sistema total de sus interrelaciones" (Bourdieu, Passeron y Chamboredon, 1979, p. 54); los conceptos operatorios son a los sistemáticos, lo que el objeto preconstruido al científicamente construido (Lenoir, 1993).

De ahí que Favereau incurra en la falacia de reificación aunque, hay que reconocerlo, de una manera muy original: ¡se la atribuye al mismo Bourdieu! Dice Favereau: "Si los campos se presentan en la forma de conjunto de relaciones y si la gramática de esas relaciones es dada por la estructura del espacio social, ¿cuál puede ser el contenido de su autonomía? La única respuesta posible, sin contradicción, es: un contenido sustancial, a falta de relacional" (Favereau, 2005, p. 309). Sin embargo, si Favereau cree ver muy claro ese error, también hay que reconocer que cuando uno analiza (no sólo los "lee") los trabajos con base empírica, como los reunidos en Las estructuras sociales de la economía (Bourdieu, 2001), se comprende más claramente la naturaleza relacional de los campos y es difícil dejar de ver la enorme capacidad explicativa de la teoría de los campos, así como el hecho de que no tiene nada que ver con el pensamiento sustancialista. Es justo decir, empero, que quizá la verdadera veta a explotar y analizar en el trabajo de Favereau vaya más en el sentido de la postura que Jean-Claude Passeron, colega y amigo de Bourdieu, mantuvo respecto de la incompatibilidad 
entre la actividad propiamente científica y la acción propiamente política (Passeron, 2003, p. 34); pero ese análisis, cuyas características e implicaciones no pueden sino sólo columbrarse ahora, sería materia de otro texto.

\section{Pensamiento Relacional-REFlexivo: ¿UN PARADIGMA TRIUNFANTE?}

El análisis de esta crítica de un economista (Favereau) a la sociología económica de Bourdieu, a la luz, por un lado, de la respuesta que otro economista (Boyer) le da y, por otro, del análisis que un economista devenido sociólogo (Lebaron) hace del campo específico (y su lógica interna) al que ambos economistas pertenecen, así como lo que el propio Bourdieu argumentara en su momento, permite contar no tanto con una apología de este último, sino más bien con un esquema analítico que facilitará comprender mejor en qué sentido se ha afirmado que sus teorías pueden apuntar hacia "un nuevo paradigma" unificador de la sociología y la economía (Sandoval, 2010).

Y se podría afirmar que representa un referente fundamental no sólo para los científicos latinoamericanos, sino para toda la sociología y la economía más allá de esta región del planeta, pues, como ha dicho Robert Castel, "Pierre Bourdieu representa un paradigma, si no es que el paradigma, de la postura sociológica" (Castel, 2003, p. 347). Léase bien: Castel no habla ad hominem, es decir, no habla de Pierre Bourdieu en tanto individuo, sino de lo que su pensamiento representa. Y lo que representa no es una teoría en particular, sino el paradigma de la postura sociológica (de hecho, de las ciencias sociales en general). No se propone, empero, que se acepte como dogma semejante afirmación sino, como todo en la ciencia, partir de ella para someterla al escrutinio y al veredicto de los hechos.

Se ha advertido que los defensores de la "descolonización del saber" sociológico y económico de América Latina tienen razón al advertir acerca de los peligros, en todo caso absurdos o malentendidos, de seguir tratando de pensar esta región del planeta desde un sistema de categorías mentales deudoras de la cultura europea, y tienen también razón en proponerse encontrar lo que de "original" puede aportar la sociología hecha en América Latina (Sandoval, 2010; 2011). Es precisamente por eso que la referencia a Bourdieu resulta pertinente, de hecho, necesaria: porque promete ser un paradigma. Y su fortaleza como paradigma radica en que no sólo constituye una teoría o un conjunto de teorías sociológicas más, sino en su implacable (e impecable) reflexividad. En resumen: no es una teoría lo que se propone probar, sino un paradigma que tiene como 
principio la crítica y la vigilancia epistemológica de las mismas teorías sociológicas y los sistemas de categorías de pensamiento desde los que las primeras se elaboran. ${ }^{16}$

La crítica de las categorías teóricas se erige como la más fundamental e indispensable tarea de cualquier científico, social o no. Como lo ha demostrado agudamente el filósofo contemporáneo John R. Searle (1997), la mejor manera de entender la realidad social es poniendo de relieve su naturaleza construida, esto es, institucional y relacional, idea que se ha podido aplicar con gran éxito en la teoría económica por Bruno Gandlgruber (2010, pp. 59-61) quien, dicho sea de paso, aborda una amplia gama de teorías institucionalistas y evolutivas distintas a la regulacionista, pero afines a la misma, y reconoce la importancia que algunas sociologías - entre las que se adivina la de Bourdieu- han tenido en las teorías institucionalistas (Gandlgruber, 2010, pp. 29). Así, se augura un futuro prometedor para las ciencias sociales. En lo que respecta a la economía, la perspectiva relacional-reflexiva ya ha dado frutos, desde la macroeconomía (los trabajos del propio Boyer) hasta la economía de las actividades más acotadas, por ejemplo, la economía campesina (Rosas y Barkin, 2009). En la sociología destacan los trabajos de los ya citados Charles Tilly, Patrick Fridenson o Loïc Wacquant. Haría falta, claro está, llevar a cabo una revisión exhaustiva de la bibliografía latinoamericana, por ejemplo, para dar cuenta del avance de este paradigma en nuestra región. ${ }^{17}$

Si bien se argumenta que es la adopción de una perspectiva relacional lo que permitiría a la sociología y a la economía superar sus limitaciones explicativas intrínsecas e, incluso, concebir su unificación (o reunificación), también se reconoce que la perspectiva individualista clásica ha desempeñado el papel de interlocutora en el proceso de construcción de las ciencias sociales, el cual puede verse como un proceso por el que el individualismo se ve paulatinamente superado. Es decir, la perspectiva relacional no se opone al individualismo (bajo todas sus formas) como su antítesis, sino como momento de resolución de la oposición

${ }^{16}$ Esto es lo que sostiene Bourdieu cuando afirma: "Si pareció necesario mostrar que muchos de los logros de la ciencia económica son perfectamente compatibles con una filosofía del agente, de la acción, del tiempo y del mundo social completamente diferente de la que producen o aceptan por lo común la mayor parte de los economistas, no fue para hacer sacrificios a una especie de pundonor filosófico, sino únicamente para intentar reunificar las ciencias sociales, con un esfuerzo por devolver a la economía a su verdad de ciencia histórica” (Bourdieu, 2000, p. 243).

${ }^{17}$ Tarea que está iniciada por el autor (Sandoval, 2010 y 2011) y que en su oportunidad se dará a conocer. 
ante una concepción colectivista de la sociedad por el cual aquel, el individualismo, encuentra su verdad.

\section{EPÍLOGO: BREVÍSIMA DIGRESIÓN EPISTEMOLÓGICA}

Pero ¿cómo es posible que dos ciencias sociales diferentes compartan un mismo paradigma, el relacional-reflexivo? ¿No corren el riesgo de confundirse? ¿Cómo y dónde se origina un paradigma como el relacional-reflexivo? A reserva de ampliar esta idea en otro artículo, se propone retomar el modelo organizativo de las ciencias desarrollado por Jean Piaget, ${ }^{18}$ en el que se diferencian cuatro niveles o estratos: uno sobre el "dominio material" de cada ciencia, que se refiere a su objeto. En un segundo nivel, el "dominio conceptual" referido a las teorías y conocimientos acerca del dominio material. En seguida, un tercer nivel correspondiente al "dominio epistemológico interno" de cada ciencia, que consistiría en el análisis crítico de sus fundamentos. Y un cuarto nivel del "dominio epistemológico derivado", en el que se analizarían las relaciones entre las diferentes ciencias y se verificaría la posibilidad de compartir los esquemas cognoscitivos más fundamentales. Entonces, se sostiene que la forma de pensamiento relacional, entre otras (como la individualista o "atomística"), pertenecería principalmente a ese nivel "epistemológico derivado".

De esta manera se explica que diferentes disciplinas científicas, como la sociología y la economía (definidas por su dominio material), compartan una u otra misma base epistemológica, o incluso que diferentes teorías (dominio conceptual) dentro de una misma disciplina se asienten en diferentes paradigmas (dominios epistemológico interno y epistemológico derivado). El hecho de que el paradigma relacional dé muestras de explicar mejor que otros uno o más dominios materiales correspondientes a diferentes disciplinas, no implica que se confundan o que una absorba a la otra, sino sólo eso: que tenemos una mejor comprensión del mundo y, por ende, como descubrieron los autores de la Enciclopedia, un mejor dominio del mundo.

\section{REFERENCIAS BIBLIOGRÁFICAS}

Álvarez-Uría, Fernando, y Varela, Julia (2009), Sociología de las instituciones, Barcelona, Morata.

\footnotetext{
${ }^{18}$ El modelo de Piaget es mucho más amplio; aquí sólo se hace referencia de manera muy general a su esquema clasificatorio de las ciencias. Para mayor precisión, véase Jean Piaget (1979 y 1987).
} 
Bronckart, Jean-Paul, y Schurmans, Marie-Noëlle (2005), "Pierre Bourdieu-Jean Piaget: habitus, esquemas y construcción de lo psicológico", en Lahire, Bernard, El trabajo sociológico de Pierre Bourdieu: deudas y críticas, Buenos Aires, Siglo XXI, pp. 181-206.

Boulding, Kenneth E. (1970), Economics as a Science, Chicago, MacGraw-Hill Book Company.

Bourdieu, Pierre (1993), Cosas dichas, Barcelona, Gedisa.

- (1998), La distinción. Criterios y bases sociales del gusto, Madrid, Taurus.

(1999a), Meditaciones pascalianas, Barcelona, Anagrama.

(1999b), La miseria del mundo, Madrid, FCE.

(2001), Las estructuras sociales de la economía, Buenos Aires, Manantial.

(2002), "Science, politique et sciences sociales", Actes de la recherche en sciences sociales, Vol. 141-142, mars, pp. 9-12. doi: 10.3406/arss.2002.2813 http:// www.persee.fr/web/revues/home/prescript/article/arss_0335-5322_2002_ num_141_1_2813. Consultado el 5 de octubre de 2011.

- (2005), El oficio de cientifico, Barcelona, Anagrama.

- (2006), Argelia 60. Estructuras económicas y estructuras temporales, Argentina, Siglo XXI.

(2007), Autoanálisis de un sociólogo, o Esto no es una autobiografía, Barcelona, Anagrama.

- (2008), Homo academicus, Buenos Aires, Siglo XXI.

- (2010), "La producción de la creencia. Contribución a una economía de los bienes simbólicos", en El sentido social del gusto, Buenos Aires, Siglo XXI, pp. 153-229.

— logo, México, Siglo XXI.

— y Chartier, Roger (2010), Le sociologue et l'historien, Marseille, Agone et Raisons d'agir.

—_, y Darbel, Alain (2003), El amor al arte. Los museos europeos y su público, Barcelona, Paidós, Paidós Estética No. 33.

—, y Wacquant, Loïc (2000, mayo), "La nouvelle vulgate planétaire", L'Amérique dans les têtes, dossier de Le Monde diplomatique, No. 11, pp. 6-7.

— y Wacquant, Loïc (2005), Una invitación a la sociología reflexiva, Buenos Aires, Siglo XXI.

Boyer, Robert (2003a), "L'art du judoka. Une sociologie aux frontières de l'économie", en Encrevé, Pierre, y Lagrave, Rose-Marie, Travailler avec Bourdieu, Paris, Champs-Flammarion, pp. 267-279. 
_ (2003b), "L'anthropologie économique de Pierre Bourdieu”, Actes de la recherche en sciences sociales, Vol. 150, décembre 2003, pp. 65-78. Recuperado de: www.persee.fr. Consultado el 4 de julio de 2011.

- (2010), "La crisis actual a la luz de los grandes autores de la economía política", Economía: Teoría y Práctica, Nueva Época, número 33, julio-diciembre de 2010, pp. 11-58.

(2011), "Macromodelación en la tradición regulacionista", curso impartido en la UNAM, México. Recuperado de: http://www.posgrado.unam.mx/economia/avisos /curso_macromodelacion/index.html. Consultado el 11 de septiembre de 2011.

Castel, Robert (2003), "Pierre Bourdieu et la dureté du monde", en Encrevé, Pierre, y Lagrave, Rose-Marie, Travailler avec Bourdieu, Paris, Champs-Flammarion, pp. 347-355.

Collins, Randall (1996), Cuatro tradiciones sociológicas, México, UAM.

Darnton, Robert (1987), La gran matanza de gatos y otros episodios en la historia de la cultura francesa, México, FCE.

Deane, Phyllis (1993), El Estado y el sistema económico. Una introducción a la historia de la economía política, Barcelona, Crítica-Grijalbo.

Desrosières, Alain (2003), "Une rencontré improbable et ses deux héritages", en Encrevé, Pierre, y Lagrave, Rose-Marie, Travailler avec Bourdieu, Paris, ChampsFlammarion, pp. 209-218.

Favereau, Olivier (2005), "La economía del sociólogo, o pensar (la ortodoxia) a partir de Pierre Bourdieu", en Lahire, Bernard, El trabajo sociológico de Pierre Bourdieu: deudas y críticas, Buenos Aires, Siglo XXI, pp. 297-368.

Foucault, Michel (1992), Microfísica del poder, Madrid, La Piqueta.

Fridenson, Patrick (2003), "L'univers incertain des entreprises”, Encrevé, Pierre, y Lagrave, Rose-Marie, Travailler avec Bourdieu, Paris, Champs-Flammarion, pp. 163-173.

Gandlgruber, Bruno (2010), Instituciones, coordinación y empresas. Análisis económico más allá de mercado y Estado, México, Anthropos/UAM-Cuajimalpa.

Garza, Enrique de la (coord.) (2000), Tratado latinoamericano de sociología del trabajo, México, FCE.

Giner, Salvador (2004), Teoría sociológica clásica, Barcelona, Ariel.

Gingras, Yves (2007), "Reflexividad y sociología del conocimiento científico", en Champagne, Patrick; Pinto, Louis, y Sapiro, Gisèle, Pierre Bourdieu, sociólogo, Buenos Aires, Nueva Visión, pp. 239-246.

Ghasarian, Christian (2008), De la etnografía a la antropología reflexiva. Nuevos campos, nuevas prácticas, nuevas apuestas, Buenos Aires, Ediciones del Sol.

Granovetter, Mark (1985), "Economic Action and Social Structure: The Problem of Em- 
beddedness", American Journal of Sociology, Vol. 91, No. 3, November 1985, pp. 481-510.

Hayek, Friedrich A. von (1958), Individualism and economic order, Chicago, The University of Chicago Press.

Held, David (2001), Modelos de democracia, Madrid, Alianza.

Lahire, Bernard (2005), El trabajo sociológico de Pierre Bourdieu: deudas y críticas, Buenos Aires, Siglo XXI.

Lebaron, Frédéric (1997), "La dénégation du pouvoir. Le champ des économistes français au milieu des années 1990", Actes de la recherche en sciences sociales, Vol. 119, septembre 1997, pp. 3-26. Recuperado de: http://www.persee.fr/web/ revues/home/prescript/article/arss_0335-5322_1997_num_119_1_3226. Consultado el 3 de marzo de 2011.

- (2007), "Los modelos económicos frente al economicismo", en Champagne, Patrick; Pinto, Louis, y Sapiro, Gisèle, Pierre Bourdieu, sociólogo, Buenos Aires, Nueva Visión, pp. 84-94.

- (2010), "Economics and sociology in the context of globalization", en World Social Science Report 2010: Knowledge Divides, Paris, International Social Science Council/UNESCO, pp. 197-198.

Lenoir, Remi (1993), “Objeto sociológico y problema social”, en Champagne, Patrick; Lenoir, Remi; Merllié, Dominique, y Pinto, Louis, Iniciación a la práctica sociológica, México, Siglo XXI, pp. 57-102.

L'Estoile, Benoît de (2003), "Entrer dans le jeu: la science comme croyance”, en Encrevé, Pierre, y Lagrave, Rose-Marie, Travailler avec Bourdieu, Paris, ChampsFlammarion, pp. 129-139.

Marengo, Luigi, y Pasquali, Corrado (2009), "El mercado, la empresa y la primacía del conocimiento", en Viale, Ricardo, Las nuevas economías. De la economía evolucionista a la economía cognitiva: más allá de las fallas de la teoría neoclásica, México, FLACSO, pp. 69-82.

Marrero, Adriana (2006), "La teoría del capital social. Una crítica en perspectiva latinoamericana", Arxius de Ciències Socials, No. 14, junio, Universidad de Valencia, pp. 73-90.

Passeron, Jean-Claude (2003), "Mort d'un ami, disparition d'un penseur”, en Encrevé, Pierre, y Lagrave, Rose-Marie, Travailler avec Bourdieu, Paris, Champs-Flammarion, pp. 17-90.

Piaget, Jean (1979), Tratado de lógica y conocimiento científico. Tomo 7: Clasificación de las ciencias y principales corrientes de la epistemología contemporánea, Buenos Aires, Paidós. 
- (1987), Introducción a la epistemología genética. Volumen 3: El pensamiento biológico, psicológico y sociológico, México, Paidós.

Pinto, Louis (2007), Pierre Bourdieu y la teoría del mundo social, México, Siglo XXI.

Poupeau, Franck (2007), Dominación y movilizaciones. Estudios sociológicos sobre el capital militante y el capital escolar, Córdoba, Ferreyra Editor. Recuperado de: http://www.pieb.com.bo/blogs/poupeau/archivos/Dominacion_FranckPoupeau. pdf. Consultado el 10 de enero de 2011.

Ringer, Fritz K. (2010), "Hacia una historia social comparativa del conocimiento", en Schriewer, Jürgen, y Kaelble, Hartmut, La comparación en las ciencias sociales e históricas, Barcelona, Octaedro, pp. 197-214.

Rosas, Mara, y Barkin, David (2009), "Racionalidades alternas en la teoría económica", Economía: Teoría y Práctica, No. 31, Nueva Época, julio-diciembre 2009, pp. 73-96.

Ryle, Gilbert (2005), El concepto de lo mental, Barcelona, Ediciones Paidós Ibérica.

Sandoval Aragón, Sergio Lorenzo (2010), "El pensamiento sociológico en los estudios del trabajo en América Latina: hacia una teoría fundamental”, en Ruiz Flores, Jesús; López Paniagua, Rosalía, y Sandoval Aragón, Sergio Lorenzo, Procesos formativos y estructuración regional de los mercados de trabajo, Guadalajara, Universidad de Guadalajara, pp. 123-147.

(2011), "Educación superior y mercados de trabajo: nuevas configuraciones teóricas en las ciencias sociales", ponencia presentada en el XXVIII Congreso Internacional de ALAS, UFPE, Recife, Brasil. Recuperado de: http://www.anais. alas2011recife.com/. Consultado el 5 de noviembre de 2011.

Schneewind, Jerome B. (2009), La invención de la autonomía: Una historia de la filosofía moral moderna, México, FCE.

Searle, John R. (1997), La construcción de la realidad social, Barcelona, Paidós Básica. Soros, George (1999), La crisis del capitalismo global, México, Plaza y Janés.

Tilly, Charles (2000), La desigualdad persistente, Buenos Aires, Ediciones Manantial.

Thompson, John B. (2003), "La transformación de la visibilidad", Estudios Públicos, No. 90, otoño, Madrid, pp. 273-296.

Viale, Ricardo (2009), Las nuevas economías. De la economía evolucionista a la economía cognitiva: más allá de las fallas de la teoría neoclásica, México, FLACSO.

Wacquant, Loïc (1993), "Bourdieu in America: Notes on the Transatlantic Importation of Social Theory", en Calhoun, Craig; LiPuma, Edward, y Postone, Moishe, Pierre Bourdieu: Critical Perspectives, Chicago, University of Chicago Press/ Cambridge Polity Press, pp. 235-262.

- (2005), "Un taller sociológico en acción: Actes de la recherche en sciences sociales", en Jiménez, Isabel (coord.), Ensayos sobre Pierre Bourdieu y su obra, México, CESU/UnAM/Plaza y Valdés, pp. 381-387. 